\title{
QPFORSETI
}

Forseti. Revista de Derecho. Volumen , No 14, Lima, 2021, pp. 131 - 156

\section{Los Convenios para evitar la Doble Imposición y su régimen constitucional de perfeccionamiento interno: ¿Una reforma esencial ante el Bicentenario de la República?}

\author{
Daniel S. Salazar Urbina*
}

Resumen. - El presente artículo analiza el problema de la exigua red de convenios para evitar la doble imposición que dispone el Perú en función del régimen constitucional para su perfeccionamiento interno, teniendo en cuenta el contexto actual demarcado por el Bicentenario de la República. La metodología empleada es cualitativa, producto de estudiar la situación desde un enfoque analítico y teórico.

\begin{abstract}
The present article analyzes the problem of the meagre network of conventions to avoid double taxation available in Peru according to the constitutional regime for its internal improvement, by consider the actual context of Bicentennial of the Republic. The methodology that we used be qualitative because we examined the situation by an analytic and theorical perspective.
\end{abstract}

Palabras claves. - Convenios para evitar la doble imposición - Perfeccionamiento interno - Régimen constitucional - Bicentenario de la República

Keywords. - Conventions to avoid double taxation - Internal improvement Constitutional regime - Bicentennial of the Republic

Abogado por la Universidad de San Martín de Porres (USMP). Practicante profesional en la División de Procesos de Recuperación de la Deuda de la SUNAT. Miembro principal del área de investigación del Centro de Estudios de Derecho Tributario de la USMP. Asociado de la Comisión de Derecho Tributario de la Sociedad Peruana de Derecho y miembro de la comisión de investigaciones de la Asociación Civil "Ius Inter Gentes" de la Pontifica Universidad Católica del Perú. 


\section{Introducción}

Durante el transcurso de la Constitución de 1979 a la de 1993, el capítulo dedicado al esquema de aprobación de los tratados, acuerdos, convenios $\mathrm{u}$ otras denominaciones que puedan atribuirse a estos mecanismos de naturaleza internacional, fue objeto de un amplio debate.

El marco constitucional anterior al vigente estipulaba una fórmula imprecisa para la revisión de un tratado a fin de calificar si su perfeccionamiento interno (fase esencial del procedimiento aplicable a todo tratado) requería o no un acto de aprobación previa. El problema, en aquel entonces, respondía a cuestiones de "exclusividad en la competencia", al margen de que, posteriormente, se esbozaron intentos legislativos que pretendían aliviar las críticas vertidas ${ }^{1}$.

El diseño que recoge la Constitución de 1993, respecto a la temática que venimos comentando, delimita una distinción entre el esquema de aprobación de los tratados de manera compleja (se requiere un acto de aprobación previa por el Legislativo, indistintamente que el Ejecutivo acate el resto de etapas para la entrada en vigor del tratado, según el artículo $56^{\circ}$ de la Carta Magna) o simplificada (no se requiere un acto de aprobación previa por el Legislativo, siendo suficiente que el Ejecutivo prosiga el curso del resto de etapas para la entrada en vigor del tratado, conforme al artículo $57^{\circ}$ del cuerpo constitucional). La aplicación de una u otra técnica de aprobación dependerá del contenido que constituye el objeto del tratado internacional (el artículo $56^{\circ}$ estipula una lista taxativa de materias que involucran su aplicación, concerniendo aplicar el artículo $57^{\circ}$ a toda temática que se no se encuentre inmersa en la mencionada lista) ${ }^{2}$.

Para el caso de una materia en particular, como son los convenios para evitar la doble imposición (CDI, en adelante), el método adoptado por la Norma Suprema para su perfeccionamiento interno es de carácter complejo. El desarrollo continuo de esta regla constitucional debió influenciar positivamente en el fortalecimiento de la estructura peruana relativa a los CDI. No obstante, la realidad es totalmente distinta.

No disponer de una amplia red de estos instrumentos vigentes a la fecha, advertir que una parte de estos mecanismos entró en vigor (pero luego fue denunciado), identificar que sobre alguno recae un debate en torno a su vigencia efectiva y anuncios de suscribir estos instrumentos pero que solo quedaron en buenas intenciones, son algunos supuestos que nos permiten afirmar que el esquema peruano de CDI se encuentra lejos de alcanzar un estándar adecuado de idoneidad. Los factores que pueden explicar esta última situación pueden ser

1 ABUGATTÁS, Gattás. Tratados que requieren la aprobación del Congreso de la República del Perú. En Agenda Internacional, Vol. XXV, núm. 37, 2019, pp.213-214.

2 FUENTES VÉLIZ, Juan Andrés. Algunas precisiones sobre la relación entre el derecho internacional y el derecho nacional peruano. En De anacronismos y vaticinios. Diagnóstico sobre las relaciones entre el derecho internacional y el derecho interno en Latinoamérica, editado por Juana Acosta López, Paola Acosta Alvarado y Daniel Rivas Ramírez, 73-75. Colombia: Universidad Externado de Colombia, 2017 \& NOVAK TALAVERA, Fabián. Los tratados y la Constitución Peruana de 1993. En Agenda Internacional, Vol.2, núm.1, 1994, p.81. 
diversos (ausencia de compromiso gubernamental, fuerza mayor, denuncias del tratado posterior a su suscripción, temor de suscribir estos acuerdos ante eventuales limitaciones en la autonomía estatal, etc.). Sin perjuicio de ello, desde nuestra perspectiva, una de las causas elementales de esta problemática recae en las insuficiencias del régimen actual para el perfeccionamiento interno de los CDI.

De ahí, que la cuestión resultante es la siguiente: ¿Puede calificarse como idóneo el régimen constitucional actual para el perfeccionamiento interno de los CDI en nuestra legislación? ¿Es necesario desarrollar una propuesta de reforma en torno a esta materia? La resolución de las interrogantes planteadas adquiere importancia no solo por involucrar un tema de elevada connotación nacional e internacional, sino, además, porque nuestro país afronta con amplias expectativas el curso del Bicentenario de la República.

En consecuencia, el objetivo del presente artículo es determinar en qué medida el esquema peruano de CDI puede concebirse como adecuado y, en consecuencia, de qué manera se amerita el desarrollo de una propuesta de reforma constitucional en torno al régimen de aprobación de los CDI.

En primer lugar, brindaremos algunos alcances respecto a los CDI y su marco normativo para su perfeccionamiento interno en el ordenamiento jurídico nacional.

En segundo lugar, estudiaremos el panorama actual de los CDI en nuestro sistema y sus problemáticas inherentes, a fin de enfatizar en el análisis de las insuficiencias del régimen constitucional actual para el perfeccionamiento efectivo e idóneo de los CDI en el marco interno.

En tercer lugar, delimitaremos algunas propuestas de técnica legislativa para la reforma del marco constitucional relativo al perfeccionamiento interno de los CDI, la finalidad que subyace en torno a las mismas y un análisis sobre su viabilidad de aplicación en la realidad, además de manifestar las expectativas que supondrán estos eventuales cambios en el contexto del Bicentenario de La República.

Finalmente, el cierre de ideas de las presentes líneas se traducirá en función de la reflexión final pertinente.

\section{Alcances sobre los CDI y su régimen constitucional de perfeccionamiento interno}

En principio, la adecuada comprensión del instituto de los CDI importa retrotraernos a lo que se conoce como la doble imposición.

La doble imposición se presenta como una situación en donde dos o más Estados imponen un gravamen respecto a una renta específica al considerar que disponen de tal derecho en virtud del ejercicio de su soberanía. Esta definición posibilita distinguir un primer contexto en donde dos o más países, respecto a un hecho o supuesto específico (ingresos, bienes) y atribuibles a un mismo sujeto en un período similar, aplican un gravamen sobre el mismo de conformidad con su 
legislación interna, conociéndose esto como doble imposición jurídica o internacional. A su vez, encontramos un segundo contexto en donde dos o más Estados aplican gravámenes sobre una misma renta o bien en el marco de un mismo período, aunque la obligación de aportar al fisco respecto a tal gravamen recae en diferentes personas y no en una sola, conociéndose esto como la doble imposición económica ${ }^{3}$.

Sobre el particular, consideramos que un caso concreto de doble imposición jurídica y/o económica puede ser solventado mediante los CDI, aunque ello dependerá de su suscripción y efectiva vigencia entre los países involucrados (y, correlativamente, que del contenido del acuerdo se observe el planteamiento de técnicas propicias que faculten prevenir la doble imposición en sus dos vertientes). Coloquemos algunos ejemplos para entender esto.

En primer lugar, tenemos a la empresa "Corporación Dial", domiciliada en Chile, pero que ha realizado inversiones en el Perú en materia de restaurantes. Tal empresa deberá soportar en el Perú una carga tributaria aproximada de un 33\% (29,5\% por impuesto a la renta de tercera categoría, adicionado a un $5 \%$ por concepto de dividendos) y cuando se derivan las utilidades a Chile, se deberán abonar un $35 \%$. Como puede apreciarse, la empresa chilena tributaría un alícuota elevada (68\%) de conformidad con la normativa impositiva peruana y chilena, lo cual incidiría negativamente en impulsar actividades económicas, en el país, por parte de actores extranjeros. Afortunadamente, el Perú cuenta con un CDI suscrito con Chile, razón por la cual se evitaría esta situación perniciosa que afecta la inversión extranjera. Esto viene a ser un ejemplo en donde se presenta una situación de doble imposición jurídica y en donde la misma ha sido aliviada en virtud del CDI vigente entre el Perú y Chile.

En segundo lugar, tenemos el supuesto de la empresa "Flandes Occidental S.A", domiciliada en el Perú y cuyo objeto social es la venta de calderas industriales y cuenta con una empresa matriz "Flanders Inc.', ubicada en Bélgica. Tal compañía, luego de declarar sus dividendos del año fiscal 2017, deberá soportar una carga tributaria del 29,5\% (al enmarcarse en el régimen general de impuesto a la renta de tercera categoría). Posterior a ello, se remesarán los dividendos hacia la empresa matriz ubicada en Bélgica, las cuales serán afectadas tributariamente al considerarse rentas de fuente extranjera (aplicándose una tasa del 34\%, correspondiente al impuesto sobre sociedades en este país). Esto viene a ser un supuesto en donde se advierte una situación de doble imposición económica, en donde la misma no ha podido ser aliviada (ante la ausencia de un CDI entre el

3 ZUZUNAGA DEL PINO, Fernando. Ponencia general: Convenios para evitar la Doble Imposición. En CDIs - Convenios para evitar la Doble Imposición, editado por IFA-Perú. Lima, Perú, IFA-Perú, pp.295-296.

4 VILLANUEVA GUTIERREZ, Walker. Doble tributación: Abusos y prevención, Conexión ESAN, https://www.esan.edu.pe/conexion/actualidad/2019/08/16/doble-tributacion-abusos-yprevencion/ 
Perú y Bélgica) $)^{5}$.

Ahora bien, es de precisar que si bien los CDI se constituyen, hoy en día, como el principal mecanismo para combatir supuestos de doble imposición, no es menos cierto que los Estados pueden acudir a otras alternativas como las medidas unilaterales (por ejemplo, exención total o parcial en la base imponible del impuesto nacional en cuanto el hecho imponible fue gravado en territorio extranjero, posibilitar que el impuesto abonado o devengado en el extranjero se adopte como gasto deducible para efectos tributarios nacionales, etc.) y/o técnicas de armonización fiscal (esta herramienta, de mayor empleo en la Unión Europea, implica que un Estado se aproxime a las estructuras tributarias de un grupo de países a efectos de solventar eventuales conflictos, aunque existen sectores doctrinarios que estiman que este marco de armonización fiscal no se orienta, directamente, a eliminar la doble imposición) ${ }^{6}$.

Por otra parte, sin importar que ante un caso particular nos encontremos ante el análisis de una doble imposición económica o jurídica, los efectos que desprende la doble tributación son semejantes: i) afectan la capacidad contributiva del contribuyente, ii) puede manifestar un trato desigual a rentas iguales, iii) constituye un obstáculo para el fomento de la inversión extranjera que coadyuve al desarrollo económico y iv) contraviene la aptitud de un esquema impositivo al incentivar índices de evasión y elusión fiscal7.

Es este complejo panorama lo que da origen al surgimiento de los CDI. Los CDI se definen como instrumentos internacionales celebrados entre dos o más Estados cuyo objetivo es prevenir situaciones de doble imposición respecto a impuestos como la renta o al patrimonio. Este aspecto puede definirse como una motivación tributaria de este mecanismo supranacional 8 .

Para cumplir con su meta principal, se procede a distribuir la potestad tributaria entre los Estados signatarios, lo que en la práctica conlleva a modificar y/o suspender la aplicación de ciertos tributos internos en alguno de los países signatarios. En aras de salvaguardar las disposiciones del tratado, los Estados suscriptores renuncian a aplicar su poder tributario en la determinación de un impuesto interno concreto (el caso típico es el impuesto a la renta). No se encuentra de más precisar que los CDI únicamente se orientan a calificar los hechos imponibles en aras de repartir la competencia tributaria entre los países firmantes,

5 ALVA MATEUCCI, Mario. La doble imposición económica y jurídica: ¿existen diferencias?, Blog PUCP, http://blog.pucp.edu.pe/blog/blogdemarioalva/2017/06/14/la-doble-imposicioneconomica-y-juridica-existen-diferencias/

6 DELGADO RIVERO, Francisco. \& FERNÁNDEZ LLERA, Roberto. Armonización fiscal y convergencia de la estructura tributaria en la Unión Europea. En Boletín Económico de ICDE, $\mathrm{N}^{\circ}$ 2907, 2007, p. 17. \& SANCHÉZ GARCÍA, Nicolás. La doble imposición internacional. En Revista de treball, economia $i$ societat, núm.16, 2000, p.9.

7 ROSADO HARO, Alberto \& SARDUY GONZÁLEZ, Mariuska. La doble tributación internacional: características y consecuencias. En Cofin Habana, Vol.12, núm.2, 2018, p.301.

8 SANTA CRUZ MIRANDA, Adolfo. La fiscalidad internacional y los convenios para evitar la doble imposición. En Quipukamayoc - Revista de la Facultad de Ciencias Contables de la UNMSM, Vol. 22, núm. 42, 2014, p.181. 
pero no a crear impuestos 9 .

Asimismo, es factible identificar otros propósitos y su correlativa motivación que desprende la suscripción de los CDI: i) se estructuran acuerdos para el intercambio de información entre las administraciones tributarias con el objeto de fortalecer la labor fiscalizadora sobre los contribuyentes para fines del CDI, lo que -en consecuencia- colabora con la prevención del fraude fiscal (motivación tributaria) y ii) facilitan un soporte jurídico sostenido y atractivo para las inversiones (motivación no tributaria) ${ }^{10}$.

De otro lado, la estructuración del contenido de los CDI se ha basado en dos modelos generalmente aceptados por la colectividad internacional. Estos son el Modelo de la Organización para la Cooperación y el Desarrollo Económico (OCDE, en adelante) y la Organización de las Naciones Unidas (ONU, en adelante).

El manejo del primer modelo es conveniente cuando las partes involucradas son Estados exportadores de capitales o con potencial de serlo y cuando el flujo comercial o de inversión es proporcionalmente similar entre los mismos. La perspectiva para combatir la doble tributación se basa en imponer mayores restricciones sobre los derechos de tributación del país fuente (se hace hincapié en el criterio de la residencia) ${ }^{11}$.

La utilización del segundo modelo es apropiada cuando se toma en consideración los requerimientos macroeconómicos de los Estados que se caracterizan por ser importadores de capital. La visión para afrontar la doble tributación se cimenta en sistematizar menores limitaciones sobre los derechos de tributación del país fuente (se enfatiza en el criterio de la fuente) ${ }^{12}$.

Después, el desarrollo de iniciativas para la celebración de los CDI implica alcanzar diversificados beneficios. Tales provechos pueden resaltarse desde dos enfoques diferentes.

Por un lado, los beneficios desde la perspectiva del Estado son los siguientes: i) obtención de un índice recaudatorio justo producto de las operaciones internacionales, ii) propugna la cooperación entre las administraciones tributarias para la lucha contra la evasión fiscal (se insertan acuerdos de intercambio de información, asistencia en la recaudación y/o de solicitud de información pertinente para el caso en concreto), iii) concuerda la práctica tributaria con la realidad generada por el desarrollo de la globalización y iv) fomenta un ambiente de certeza en las inversiones (al otorgarse un indicador positivo a la inversión

$9 \quad$ Ibid, p.182.

10 Ibid, pp. 182-183.

11 HALKA, Dominika \& TREPELKOV, Alexander \& TONINO, Harry. Manual de las Naciones Unidas en temas específicos sobre la administración de convenios de doble tributación para países en desarrollo. New York: Naciones Unidas, 2015, pp.7-8.

12 Íbid, pp. 8-9. 
extranjero y, especialmente, seguridad, en torno a los elementos que se negocian) ${ }^{13}$.

De otro lado, los provechos desde la perspectiva del inversionista son los siguientes: i) los convenios delimitan los métodos que aliviarán y/o neutralizarán la doble imposición, no pudiendo ser modificados por los países contratantes, ii) no se admite la posibilidad que un CDI emita una obligación tributaria no contemplada en la ley interna, iii) se cuenta con la certeza que se protegerán sus legítimos intereses a través del procedimiento amistoso en donde la administración tributaria del país objeto de inversión interviene en la resolución de eventuales controversias y iv) la inclusión del principio de no discriminación en el CDI otorga un margen fiabilidad una vez realizada la inversión, debido a que no se modificará la política interna del país concreto a efectos de imponer al inversionista el pago de mayores impuestos a comparación de sus residentes ${ }^{14}$.

Sin embargo, también es posible advertir que los CDI pueden presentar ciertas desventajas: i) limitan el deber estatal de resguardar su base imponible y correlativa recaudación y ii) restringe la autonomía para modificar impuestos sobre la renta, que puede devenir en un menor índice recaudatorio ${ }^{15}$.

Expuesto lo anterior, en aras de comprender los alcances del régimen constitucional de aprobación interna de los CDI, es necesario desglosar el contenido de los artículos 56 y 57 de la Constitución de 1993.

Por un lado, el artículo $56^{\circ}$ nos indica lo siguiente:

"Los tratados deben ser aprobados por el Congreso antes de su ratificación por el Presidente de la República, siempre que versen sobre las siguientes materias: 1. Derechos Humanos. 2. Soberanía, dominio o integridad del Estado. 3. Defensa Nacional. 4. Obligaciones financieras del Estado. También deben ser aprobados por el Congreso los tratados que crean, modifican o suprimen tributos; los que exigen modificación o derogación de alguna ley y los que requieren medidas legislativas para su ejecución." (el énfasis es nuestro)

De otro lado, el artículo $57^{\circ}$ manifiesta lo siguiente:

"El Presidente de la República puede celebrar o ratificar tratados o adherir a éstos sin el requisito de la aprobación previa del Congreso en materias no contempladas en el artículo precedente. En todos esos casos, debe dar cuenta al Congreso. Cuando el tratado afecte disposiciones constitucionales debe ser aprobado por el mismo procedimiento que rige la reforma de la Constitución, antes de ser ratificado por el Presidente de la República. La denuncia de los tratados es potestad del Presidente de la República, con cargo de dar cuenta al Congreso. En el caso de los tratados sujetos a aprobación del Congreso, la denuncia requiere aprobación previa de éste." (el

13 ECHAIZ MORENO, Daniel. Los convenios para evitar la doble tributación. En Derecho \& Sociedad, núm.53, 2009, p.138.

14 BORJAS HUARCAYA, Juan de Dios, «Los convenios para evitar la doble imposición y su aplicación en las empresas nacionales que prestan servicios de ingeniería en el Perú hasta el año 2010» (tesis de maestría, Universidad Nacional Mayor de San Marcos, 2012), 117.

15 ECHAIZ MORENO, Daniel, op.cit, p.139. 
énfasis es nuestro)

Los aspectos resaltados de estos artículos nos explican la fórmula de aprobación constitucional que subyace en torno a los CDI. Al involucrar estos mecanismos internacionales, en el desarrollo de la finalidad de distribución de la competencia tributaria entre los países intervinientes, una probable modificación y/o suspensión (no creación) de tributos vigentes en el marco jurídico peruano (por ejemplo, el impuesto a la renta, como se indicó previamente), se activa el ámbito reseñado por el artículo $56^{\circ}$ al ameritar una aprobación del CDI -anterior a su ratificación- por parte del Legislativo (control ex ante del tratado, en función del carácter complejo que emana este supuesto) ${ }^{16}$.

De ahí, que la labor del artículo $57^{\circ}$ no es, sino, confirmar que el Presidente de la República solo puede celebrar y ratificar unilateralmente los tratados que no versen sobre temáticas incluidas en la lista positiva del artículo $56^{\circ}$ (lo cual no es el caso de los CDI), sujetándose el mecanismo supranacional, en este caso, a su presentación al Congreso posterior a su entrada en vigor para su análisis correspondiente (control ex post del tratado, en razón de la particularidad simplificada que desprende este supuesto) ${ }^{17}$.

Es importante precisar que sin importar que un tratado internacional haya sido aprobado bajo la fórmula del artículo $56^{\circ}$ (tratado ley) y/o del artículo $57^{\circ}$ (tratado ejecutivo), ello no influye en el rango constitucional que adquieren al momento de ser incorporados al derecho nacional. En otros términos, tal procedimiento de aprobación solo adquiere relevancia para efectos de identificar la competencia del órgano que efectúa la recepción del acuerdo en el plano interno, pero no incide en el rango constitucional que se atribuye a los convenios supranacionales ${ }^{18}$.

A pesar de haberse explicado la lógica que se colige en torno al marco constitucional para el perfeccionamiento interno de los CDI, no podrían faltar dudas respecto al camino que debe seguir el instrumento para su perfeccionamiento correspondiente. En específico, si a partir de una lectura integral de un tratado concreto no sea muy claro que el mismo modificará y/o suspenderá la aplicación de un tributo interno. En otros términos, si la estructuración de los CDI como herramienta para combatir la doble imposición siempre se sujetará a los términos del artículo $56^{\circ}$ de la Constitución (control ex ante del tratado) o si, por el contrario, puede llegar a seguir la línea directriz del artículo $57^{\circ}$ de la Carta Magna (control ex post del tratado).

Para tal propósito, una iniciativa que absuelve estas dudas lo constituye el "Proyecto de Ley No 2571/2017-CR, Ley de Desarrollo Constitucional sobre el Perfeccionamiento Interno de los Tratados", al confirmar en su artículo 10.4 que la regla relativa a que un tratado puede crear, modificar y/o suprimir tributos (control ex ante o complejo, contemplado en el artículo 56 de la Carta Magna) es

16 Sentencia del Tribunal Constitucional. Exp. 00002-2009-PI/TC, fundamento 60.

17 Íbid., fundamento 75.

18 MONGE MORALES, Gonzalo. Un vistazo al Derecho Constitucional a través del Derecho Internacional. Entrevista a Juan José Ruda Santolaria. En Themis Revista de Derecho, Núm.67, p.181. 
de aplicabilidad cuando el instrumento establece regímenes para prevenir la doble imposición tributaria (CDI).

Ahora bien, considerando que delimitar regímenes para prevenir la doble imposición a través de los CDI puede colisionar con el principio constitucionaltributario de reserva de ley (los presupuestos para la creación, modificación, exoneración o derogación de los tributos, se realizan en virtud de una norma con rango legal emitida por el Congreso, salvo excepciones ${ }^{19}$ ), adquiere mayor firmeza constitucional que el trámite de ratificación de los CDI requiere de una aprobación previa por el Legislativo (perfeccionamiento interno) para su entrada en vigor.

A modo de complemento, es menester tener en consideración lo que promulgan otros cuerpos normativos internos sobre el régimen de perfeccionamiento de los tratados en general (entre ellos, los CDI en su calidad de instrumentos para evitar la doble imposición). En esa línea, encontramos la Ley N²6647 y el Decreto Ley $\mathrm{N}^{\circ} 25883$.

Por un lado, del primer cuerpo normativo mencionado resaltamos lo siguiente: i) la aprobación legislativa de los tratados de conformidad con los términos del artículo $56^{\circ}$ de la Constitución se efectúa mediante una resolución legislativa (emitida por el Legislativo) y se ratifica mediante un decreto supremo (por parte del Ejecutivo), siendo que la aprobación de los tratados acorde con el artículo $57^{\circ}$ de la Carta Magna solo requiere la emisión del decreto supremo por el Ejecutivo (artículo $2^{\circ}$ ); ii) la incorporación al derecho nacional y entrada en vigor de los tratados celebrados y perfeccionados, según el procedimiento aplicable a cada caso concreto, se sujeta al cumplimiento de las condiciones delimitadas en el mecanismo supranacional respectivo (artículo $3^{\circ}$ ); iii) se debe publicar en el diario oficial (El Peruano, en la actualidad) el texto íntegro del instrumento y sus anexos (de corresponder), así como indicar el número y fecha de la resolución legislativa o decreto supremo que lo aprobó y/o ratificó en un plazo máximo de treinta días hábiles contados a partir de su recepción por el diario oficial (artículo $4^{\circ}$ y $\left.5^{\circ}\right)^{20}$ y iv) la denuncia, modificación y/o suspensión de aquellos tratados válidamente celebrados, perfeccionados e incorporados al derecho nacional, solo podrá realizarse según los preceptos que establezca el propio mecanismo y, en su defecto, según lo predispuesto por las normas generales del derecho internacional (artículo $\left.7^{\circ}\right)$

Por otra parte, del segundo cuerpo legislativo citado rescatamos la potestad otorgada al ministro de economía y finanzas para negociar y suscribir con otros Estados, en representación de la administración gubernamental peruana, convenios bilaterales para prevenir la doble tributación y evasión tributaria $\left(\right.$ artículo $\left.1^{\circ}\right)$.

19 Sentencia del Tribunal Constitucional. Exp. 1837-2009-PA/TC, fundamento No 12.

20 Sentencia del Tribunal Constitucional. Exp. 00021-2010-AI/TC, fundamento No 22. 


\section{Realidad y dilemas de los DCI en el Perú: Incidencia del régimen constitucional de perfeccionamiento interno en la compleja situación}

Si bien se tiene registro de vulneraciones a los Derechos Humanos por parte de empresas desde hace ya un par de siglos atrás, la regulación en el ámbito del Derecho Internacional de los Derechos Humanos recién se desarrollaría en la segunda mitad del siglo XX. No obstante, es a partir del siglo XXI que veríamos normas más modernas que buscan hacerle frente a los desafíos contemporáneos. Veamos pues, desde una perspectiva histórico-jurídico, cómo se ha desarrollado la regulación internacional a las empresas transnacionales en materia de Derechos Humanos.

A la fecha, el Perú cuenta con ocho CDI suscritos, ratificados y vigentes. A esto debe adicionarse el régimen dispuesto por la Decisión 578 que no es, stricto sensu, un CDI (producto que estos convenios se celebran entre Estados y, encontrándonos, en el presente caso, ante una norma emitida por la Comisión de la Comunidad Andina - CAN), sino que se configura como una norma supranacional que dispone el mismo objetivo que los CDI (evitar la doble tributación) y a la que se encuentra sometido el Perú en conjunto con el resto de Estados que integran la CAN.

La mayor parte de ellos fueron estructurados bajo el modelo de convenio de la OCDE, aunque también existe una porción desarrollada en función del modelo de la ONU. Para comprender la premisa anterior, nos remitimos al siguiente gráfico:

Gráfico $N^{\circ}$ 1: Instrumentos para prevenir la doble imposición celebrados y vigentes en el Perú

\begin{tabular}{|c|c|c|}
\hline Convenio / Norma & Modelo & Entrada en vigor \\
\hline Perú - Chile & OCDE & $01 / 01 / 2004$ \\
\hline Perú- Canadá & OCDE & $01 / 01 / 2004$ \\
\hline $\begin{array}{c}\text { Perú - Comunidad } \\
\text { Andina }\end{array}$ & ONU & $01 / 01 / 2005$ \\
\hline $\begin{array}{c}\text { Perú - Brasil } \\
\text { Perú - México }\end{array}$ & OCDE & $01 / 01 / 2010$ \\
\hline $\begin{array}{c}\text { Perú - República de } \\
\text { Corea }\end{array}$ & OCDE & $01 / 01 / 2015$ \\
\hline Perú - Suiza & OCDE & $01 / 01 / 2015$ \\
\hline Perú - Portugal & OCDE & $01 / 01 / 2015$ \\
\hline Perú - Japón & OCDE & $29 / 01 / 2021$ \\
\hline
\end{tabular}




\begin{tabular}{|l|l|c|}
\hline & $\begin{array}{c}01 / 01 / 2022 \text { (para el caso } \\
\text { de tributos de } \\
\text { periodicidad anual) }\end{array}$ \\
\hline
\end{tabular}

Fuente: Elaboración propia 2122

El contenido de estos convenios celebrados a la fecha nos trae a colación interesantes disposiciones para el estudio del derecho tributario internacional: i) la concepción del principio de establecimiento permanente, ii) esquematización de reglas para la aplicación de intereses o ganancias de capital, iii) la mención expresa que el objetivo del CDI es prevenir la evasión fiscal, aunque también se extiende a la elusión fiscal (convenio con Japón), iv) sistematización de mecanismos para la solución de controversias sobre la atribución de potestad tributaria, v) impulso de la asistencia mutua para la recaudación de impuestos, vi) estructuración de la tributación compartida como regla general y tributación exclusiva como excepción, entre otras.

Lo hasta aquí reseñado expone el marco interno vinculado a los CDI. La disposición de una red de ocho CDI (más una norma supranacional de la CAN para evitar la doble imposición), estructurados bajo los modelos imperantes en la sociedad internacional (OCDE y ONU) y la incorporación de reglas con suma importancia para el análisis de los CDI implicaría -en teoría- un conjunto de esfuerzos por disponer de un agrupado de tratados efectivos que coadyuven a potenciar el crecimiento sostenido del país y las actividades económicas internacionales.

No obstante, como se adelantó en líneas introductorias, el marco peruano de mecanismos para evitar la doble imposición se encuentra lejos de alcanzar un estándar adecuado de idoneidad. Ello, porque ha sido factible advertir una serie de dilemas durante el transcurso del tiempo.

En primer lugar, ubicamos CDI que fueron suscritos, aprobados por el Congreso, ratificados y que entraron en vigor, pero posteriormente fueron denunciados y sobre los cuales no se ha realizado una nueva propuesta de tratado en el hoy en día. Este viene a ser el caso del CDI entre el Perú y Suecia ${ }^{23}$.

En segundo lugar, encontramos CDI que fueron suscritos, pero no fueron aprobados por el Congreso y sobre los cuales no se ha realizado una nueva

$21 \mathrm{Al}$ respecto, la mención del criterio de la residencia en el artículo $1^{\circ}$ de cada Convenio (ámbito de aplicación) es el aspecto que determina sustancialmente la adhesión del instrumento concreto al modelo OCDE. Asimismo, la influencia preponderante del modelo ONU en la Decisión 578 se desprende de lo que estipula su artículo $3^{\circ}$ (el gravamen de las rentas dependerá de la fuente productora).

22 La fecha de entrada en vigor de cada instrumento internacional, así como sus datos correlativos (suscripción, aprobación, etc.), puede apreciarse en la primera página del texto respectivo mediante la web institucional del Ministerio de Economía y Finanzas. https://www.mef.gob.pe/es/?option=com_content\&language=esES\&Itemid $=100878 \& l a n g=e s-E S \& v i e w=$ article\&id $=302$

23 El mismo fue suscrito en 1966 y denunciado por Suecia el 02 de junio de 2006. 
propuesta de tratado a la fecha. Este es el caso del CDI entre el Perú y España24.

En tercer lugar, identificamos una situación en donde el instrumento fue suscrito, aprobado por el Congreso, ratificado y que entró en vigor, pero sobre el cual existe un debate sobre su efectiva vigencia. Este es el caso del régimen para evitar la doble imposición entre el Perú y la CAN (Bolivia, Colombia y Ecuador) ${ }^{25}$.

En cuarto lugar, hallamos CDI cuya intención de negociarse fue anunciada por la autoridad gubernamental, pero hasta la fecha no existen mayores novedades sobre el particular. Este es el caso de los CDI con Estados Unidos, España, Italia, Francia, Reino Unido, Suecia y Tailandia ${ }^{26}$. Particularmente, la situación de no disponer un CDI con España, Estados Unidos y Reino Unido es lo más preocupante, considerando que son inversionistas de estos países los que representan el mayor porcentaje de inversión en el país (alrededor del 47\%).

La conjugación de estos cuatro dilemas constituye un evidente reflejo de la compleja situación interna en materia de CDI: la disposición de una escasa red en torno a esta clase de mecanismos supranacionales.

$\mathrm{Al}$ respecto, es necesario recordar que la relevancia de contar con un amplio repertorio de CDI obedece a lo fundamental que viene a ser el establecimiento de un agrupado de instrumentos internacionales que colaboren tanto a empoderar el crecimiento nacional (mediante la inversión), como al fomento de la participación nacional en el ámbito internacional (a través de las actividades económicas). En líneas anteriores, resaltamos que los CDI otorgan una variedad de provechos para el crecimiento interno como externo de un Estado concreto (fomento de ambiente de certeza para las inversiones, lucha contra la evasión fiscal, colaboración entre administraciones tributarias, etc.)

Estas últimas ideas adquieren mayor delicadez si traemos a colación el conocido anhelo del Perú ingresar a la OCDE. Como se conoce, uno de los aspectos claves para el ingreso a este organismo supranacional es la disposición de una estructura

24 El cual fue suscrito el 06 de abril de 2006 y no aprobado a raíz de un dictamen emitido por la Comisión de Relaciones Exteriores del Parlamento.

25 Si bien la entrada en vigor de la Decisión N578 responde al principio de aplicación directa de las normas del sistema andino al marco interno de los Estados miembros (Decisión $\mathrm{N}^{\circ} 472$ ), lo cierto es que esta última Decisión, al equipararse a un tratado y requerir una modificación del texto constitucional, necesitaba de una aprobación previa por parte del Congreso (artículo $56^{\circ}$ de la Carta Magna) al implicar una transferencia de competencias legislativas a favor de organismos supranacionales (CAN), lo cual no se dio en aquel entonces. Esta situación no encontraba alguna excepción en otra parte del texto constitucional, por lo que se cuestionaba la afirmación relativa a su efectiva vigencia en el ordenamiento jurídico: VILLAGRA CAYAMANA, Reneé. Identificación de los criterios de sujeción de las rentas en los CDIs celebrados por el Perú. En CDIs - Convenios para evitar la Doble Imposición, editado por IFA-Perú. Lima, Perú, IFA-Perú, pp. 680682.

26 VILLAGRA CAYAMANA, Reneé. Los Convenios Bilaterales para evitar la Doble Imposición suscritos por los países Miembros de la Comunidad Andina con terceros países: evaluación de la aplicación del Anexo II de la Decisión 40 a los 33 años de su aprobación. En Derecho E Sociedad, núm.24, 2005, p.121. 
tributaria eficiente, sostenible y transparente, en todas sus vertientes ${ }^{27}$. Los CDI no son la excepción a esta regla.

Si comparamos el catálogo de CDI del Perú con el de Chile, Colombia y México (algunos de los países miembros de la OCDE en América Latina), identificaremos que los avances de tales Estados sobre la materia objeto de análisis es sustancialmente diferente al Perú. Por un lado, Chile ${ }^{28}$ dispone de treinta y tres CDI vigentes y otros cinco suscritos en trámite de aprobación para su entrada en vigor. De otro lado, Colombia ${ }^{29}$ cuenta con un estimado de once CDI vigentes y otros cuatro suscritos en trámite de aprobación para su entrada en vigor. En tanto, México ${ }^{30}$ cuenta con un aproximado de setenta CDI vigentes en la actualidad.

Como podrá observarse, existe una diferencia sustancial, en términos cuantitativos, entre el esquema de CDI de otros países latinoamericanos (que integran la OCDE) y nuestro sistema interno. $\mathrm{Al}$ respecto, debemos precisar que, si bien la disposición de una cuantiosa red de mecanismos para combatir la doble imposición no necesariamente podría asociarse con un estándar de eficiencia en materia de CDI, lo cierto es que la idoneidad de esta situación se enmarca en la articulación de esfuerzos gubernamentales por impulsar la acogida de mecanismos que influyan positivamente en la situación del contribuyente. Esto se ve retribuido cuando a mayor cantidad de CDI celebrados y vigentes en un Estado concreto, se incrementan las posibilidades que inversionistas de diferentes países del mundo manifiesten su intención de concurrir en tal mercado.

Ahora bien, las diferencias también pueden hallarse desde una perspectiva cualitativa, siendo que su correlativo sustento parte de las desventajas que emanan de estos tratados internacionales.

El legislador nacional siempre ha observado con cierto recelo a los CDI en función de que considerar latente la probabilidad de que los mismos denoten obstáculos para que el aparato gubernamental pueda resguardar su base imponible y/o limite la autonomía para modificar impuestos sobre la renta y, en consecuencia, se le impida alcanzar un estándar efectivo e idóneo de recaudación, con lo cual se afectaría la previsión de los objetivos delineados en su política fiscal para un rango de tiempo concreto. La demostración de tal grado de suspicacia se ha manifestado a través del establecimiento de un filtro necesario para la aprobación del tratado

27 Para un estudio pormenorizado sobre el panorama tributario del Perú en su camino hacia la OCDE, sugerimos ver: ARIAS MONTOYA, Luis. El Perú hacia la OCDE: La agenda pendiente para la política tributaria 2018-2021. Lima: Grupo de Justicia Fiscal del Perú, 2018.

28 El reporte sobre la actualidad y avances de Chile en materia de CDI puede apreciarse en: Servicio de Impuestos Internos. Convenios Tributarios Internacionales/ International Tax Conventions, SII, https://www.sii.cl/normativa_legislacion/convenios_internacionales.html

29 El reporte sobre la actualidad y avances de Colombia en materia de CDI puede revisarse en: Dirección de Impuestos y Aduanas Nacionales. Acuerdos para eliminar la doble tributación en materia de impuestos sobre la renta, DIAN, https://www.dian.gov.co/normatividad/convenios/Paginas/ConveniosTributariosInternacio nales.aspx

30 El reporte sobre la actualidad y avances de México en materia de CDI puede comprobarse en: Gobierno de México. Búsqueda de Tratados, Gobierno de México, https://aplicaciones.sre.gob.mx/tratados/consulta_nva.php 
(perfeccionamiento interno), el cual no ha sido exclusivo en nuestra Carta Magna actual, sino, además, se manifestó en la Constitución de 1979, en donde todo tratado debía ser aprobado por el Congreso (artículo $102^{\circ}$ ), así como en la Constitución de 1933, en la que el instrumento debía someterse a la aprobación del Consejo de Ministros (artículo 154, numeral 20). En pocas palabras, las desventajas que emanan de los CDI han desempeñado un rol fundamental en la evolución del contexto peruano sobre los instrumentos supranacionales para prevenir la doble imposición.

En esa medida, recordemos que en líneas introductorias mencionamos que existen factores que, en general, han influenciado en la disposición de una exigua red de instrumentos para prevenir la doble imposición. En nuestra posición, los siguientes: i) falta de compromiso de los gobiernos de turno para llevar adelante el proceso, ii) discrepancias entre el representante nacional e internacional en la etapa de negociaciones, iii) circunstancias de fuerza mayor y iv) dificultades para el perfeccionamiento interno del tratado en virtud del régimen constitucional y/o legal interno aplicable. Como es de ver, para fines del presente trabajo nos centraremos en este último aspecto.

Como bien se expuso en líneas precedentes, la finalidad del legislador constitucional para propugnar un esquema de aprobación previa de los CDI (perfeccionamiento interno) se enmarca en la necesidad de contrarrestar las desventajas que desprenden estos acuerdos: limitaciones a la autonomía estatal para resguardar la base imponible y/o modificar determinados tributos.

Los actores que cuestionan a aquellos que exhortan al aparato estatal al desarrollo de mayores esfuerzos para aumentar el reducido repertorio de CDI expresan su respaldo al expresado propósito del legislador constitucional respecto al método de perfeccionamiento interno de los CDI (requisito de aprobación previa contemplado en el artículo $56^{\circ}$ de la Constitución), al actuar tal precepto constitucional como una especie de límite sobre los mismos. La visión, refieren, no debe recaer en negociar porque sí los CDI, producto de que ellos pueden implicar normas laxas que transgredan la potestad tributaria del Estado. Señalan que lo más conveniente es ser prudentes antes de avocarnos -rápidamente- a seguir las etapas correspondientes para la entrada en vigor de un $\mathrm{CDI}^{31}$.

Si bien compartimos que el trámite de entrada en vigor de un CDI es un asunto de vasta complejidad $\mathrm{y}$, por ende, requiere un grado de prudencia y análisis para llevar adelante el procedimiento, no por ello debemos confundir este margen de prudencia a mirar con una aparente desconfianza los CDI por el simple hecho de que la potestad tributaria del Estado se encuentra inmersa en el asunto. En efecto, la celebración de estos convenios tributarios puede llegar a afectar la autonomía estatal, aunque no por ello la situación se tornará en perniciosa para dicho país.

Ello, debido a que la negociación, suscripción, perfeccionamiento interno y

31 ECHAIZ MORENO, Daniel. Los convenios para evitar la doble tributación. En Derecho E Sociedad, núm.53, 2009, p.137. 
posterior ratificación del CDI, para su entrada en vigor, reportará mayores beneficios (los cuales pueden verse, como se explicó anteriormente, desde la perspectiva del Estado como del inversionista, teniendo como ejemplo la obtención de un índice recaudatorio justo, cooperación entre administraciones tributarias, generación de un contexto de certeza para las inversiones, inclusión del principio de no discriminación, entre otros) que perjuicios (limitación de la autonomía estatal y restricciones para modificar impuestos sobre la renta), lo cual responde a una situación en donde se cumple, favorablemente, con el principio de análisis costo-beneficio. Vale recordar que tal principio importa una metodología en donde se evalúa si un proyecto, medida, programa, política y/o intervención es conveniente en términos de generar bienestar social, en la medida que los beneficios (provechos) sean mayores que los costos (perjuicios) y no viceversa ${ }^{32}$.

De ahí que, lejos de estructurar obstáculos que pretendan retardar la ampliación del marco de CDI en cualquiera de sus etapas, somos de la opinión que lo indispensable es otorgar mayor celeridad a este trámite de manera transversal a todas las fases que conducirán a la entrada en vigor del tratado tributario.

Bajo la fórmula contemplada en el artículo $56^{\circ}$ de la Constitución para el perfeccionamiento interno de los CDI, identificamos que existe una considerable diferencia de tiempo que transcurre entre la suscripción y la aprobación de los CDI firmados por el Perú. La práctica nos enseña que luego de la suscripción (por el Ejecutivo) transcurre poco tiempo para derivar el texto del convenio al Parlamento para su aprobación correspondiente. Lo preocupante, es que entre la fecha de remisión del texto y la decisión de aprobar o no el CDI (por el Legislativo) puede requerirse un promedio de tiempo entre 1 a 2 años ${ }^{33}$.

Del mismo modo, el dilema puede advertirse desde la otra cara de la moneda. Esto es, visualizar retardos del Ejecutivo para remitir el texto para su aprobación por el Congreso, siendo que este último lo aprobó en un tiempo menor al del promedio ${ }^{34}$. En otros términos, la óptica constitucional para el perfeccionamiento interno de los CDI denota deficiencias para su eficiente aplicación producto de las demoras incurridas tanto por el Ejecutivo como el Legislativo en cada caso particular.

Son estos aspectos los que permiten cuestionarnos si el marco constitucional actual que impone una aprobación previa de los CDI (para su perfeccionamiento interno) coadyuva al objetivo expuesto de otorgar mayor celeridad al trámite de entrada en vigor de los CDI y, en consecuencia, si se amerita proponer un modelo de reforma constitucional.

Si bien los retrasos incurridos pueden obedecer a la abundante carga

32 ORTEGA GUAZA, Bienvenido. Análisis Coste-Beneficio. En eXtoikos, núm.12, 2012, p.147.

33 Este es el caso del CDI con Brasil (fue remitido al Congreso el 21 de junio de 2006 y aprobado por el mismo el 21 de mayo de 2008) y el CDI con los Estados Unidos Mexicanos (fue remitido al Congreso el 23 de enero de 2012 y aprobado por el mismo el 23 de diciembre de 2013).

34 Ejemplos de ello lo constituyen el CDI con Suiza (suscrito el 21 de setiembre de 2012, remitido al Congreso el 28 de octubre de 2013 y aprobado el 23 de diciembre de 2013) y el CDI con Japón (suscrito el 18 de noviembre de 2019, remitido al Congreso el 24 de septiembre de 2020 y aprobado por el mismo el 27 de diciembre de 2020). 
administrativa que predomina en los ministerios (Ejecutivo) o a su necesaria derivación preliminar a una comisión especializada antes de su aprobación en el pleno (Legislativo), esto no puede ser excusa suficiente para restar la prontitud debida al trámite de incorporación de los CDI al ordenamiento jurídico. Todo lo contrario, al derivarse amplios beneficios de su celebración, con mayor razón, se deben articular esfuerzos entre ambos poderes estatales para dotar de rapidez a las diligencias necesarias en aras de agilizar el trámite correspondiente de los CDI.

De otro lado, considerando que la entrada en vigor de los CDI se origina luego de unos meses y/o al año siguiente de la fecha de ratificación del tratado (según los términos correspondientes a cada CDI), la activación de lo primero depende de instar lo segundo de manera célere. La experiencia reseña que luego de emitirse la resolución legislativa que aprueba el CDI por el Legislativo, no discurre mucho tiempo en promulgarse el decreto supremo que ratifica el convenio tributario ${ }^{35}$.

Si para activar la referida atribución de ratificar el tratado se requiere la emisión de la correspondiente resolución legislativa (aprobación previa) y, sin embargo, la misma no se produce de forma rápida a raíz de comportamientos tanto del Legislativo como del Ejecutivo (según el caso en particular, reiteramos), una vez más nos preguntamos: ¿Es suficiente el régimen constitucional actual sobre el perfeccionamiento de los CDI para una efectiva inserción de los mismos en nuestro ordenamiento jurídico?

La respuesta, evidentemente, deviene en negativa. La redacción actual del texto constitucional es imperfecta para alcanzar el propósito de ampliar nuestra red de CDI. En ese sentido, considerando las ideas expuestas hasta aquí, adquiere sustento la idea de llevar a cabo un proceso de reforma constitucional al respecto.

No podrían faltar opiniones que califiquen como apresurado la mentalidad de reformar el esquema constitucional de perfeccionamiento interno de los CDI. Esto, al ampararse en que la técnica legislativa que emplean otros países de la región latinoamericana (por ejemplo, Chile, Colombia y México, anteriormente mencionados), es similar a la del Perú ${ }^{36}$.

Si bien llevar adelante un procedimiento de reforma constitucional implica variaciones sustanciales para el curso de la vida de una nación, no es menos cierto que su activación obedece a la imperiosidad de modificar y/o fortalecer una vertiente específica de un Estado (el artículo $56^{\circ}$ de la Constitución) luego de materializarse una ponderación entre los provechos y desperfectos que, hasta antes de la intención de reforma, denotó tal vertiente y siempre y cuando los desperfectos superaban los provechos.

35 Algunos ejemplos lo conforman el CDI con Corea (aprobado el 26 de diciembre de 2013 y ratificado el 26 de febrero de 2014) y el CDI con México (aprobado el 23 de diciembre de 2013 y ratificado el 16 de enero de 2014).

36 Al respecto, la regla de la aprobación previa de los CDI por parte del Congreso de tales países latinoamericanos es mencionada en la Constitución Política de los Estados Unidos Mexicanos (artículo $76^{\circ}$, numeral I), la Constitución Política de Colombia (artículo $224^{\circ}$ ) y la Constitución Política de Chile (artículo 54º). 
Teniendo en cuenta que los CDI vigentes en el Perú fueron desarrollados bajo la óptica del artículo $56^{\circ}$ de la actual Norma Suprema, hemos advertido que a pesar de existir una inspiración legislativa para imponer un procedimiento de aprobación previa para el perfeccionamiento interno de los CDI, proseguir con el enfoque literal que contiene el artículo citado solo coadyuvará a que nuestro sistema persista en un camino de retrocesos y dificultades para alcanzar a otros países de la región con mayor desarrollo en materia de CDI y que, precisamente, han logrado el objetivo aspirado por el Perú: integrar la OCDE. Es evidente, entonces, que los desperfectos superan a los provechos en este marco.

En esa línea, si observamos que la técnica empleada para un mismo fin (aprobar los CDI) es similar entre nuestro país y otros Estados del continente (Chile, Colombia y México) y, sin embargo, los resultados obtenidos son disímiles (los países reseñados cuentan con un mayor número de CDI vigentes y otros en proceso para su entrada en vigor, a comparación del Perú), se torna en imprescindible formular un mecanismo de cambio a tal situación (la reforma de la Constitución) y, con mayor razón, teniendo en cuenta las circunstancias concretas que puede afrontar cada país (el Bicentenario de la República, en nuestro caso).

Absueltas las observaciones expuestas, el siguiente paso es manifestar mayores alcances sobre la forma de llevar a cabo el citado procedimiento de reforma constitucional respecto a la materia objeto de análisis en el presente artículo. Esta labor será desarrollada con mayor detalle en la sección venidera.

\section{La reforma del marco constitucional de aprobación de los CDI: Propuestas legislativas, alcances, viabilidad y expectativas ante el Bicentenario de la República}

Nos encontramos ante un contexto de suma relevancia para el país tal y como lo es el Bicentenario de La República del Perú. Este evento, sin duda alguna, supone una inmejorable oportunidad para preservar y reforzar la estabilidad social, económica e institucional, de la nación. Alcanzar esta aspiración podría lograrse mediante la promoción de los derechos fundamentales, la mejora en la provisión de servicios públicos, impulso de una política económica consistente y sólida, el cierre de brechas de infraestructura, la protección del medio ambiente, entre otros. Justamente, tales aspectos han sido tomados en consideración por parte de la agencia gubernamental peruana, producto de establecer seis objetivos estratégicos ${ }^{37}$ como parte del Plan Bicentenario.

Ahora bien, en acápites anteriores reseñamos que el marco actual para el perfeccionamiento interno de los CDI se encuentra distante de alcanzar un estándar de idoneidad. La temática abordada adquiría sensibilidad no solo por su importancia para el curso de la vida en sociedad, sino, además, por hacerle frente

37 1) Derechos fundamentales y dignidad de las personas, 2) Oportunidades y acceso a los servicios, 3) Estado y gobernabilidad, 4) Economía, competitividad y empleo, 5) Desarrollo regional e infraestructura y 6) Recursos naturales y ambiente. 
-en el hoy en día- a un panorama de amplia responsabilidad para nuestro aparato estatal: el Bicentenario de La República.

Bajo ese panorama, incidíamos en lo imprescindible que viene a ser la estructuración de un bosquejo de reforma constitucional respecto al método de perfeccionamiento interno de los CDI. Este aspecto es clave para poder cumplir con la aspiración de impulsar una ampliación de la red interna de CDI y, al mismo tiempo, coadyuvar con la ejecución de los objetivos estratégicos delineados por el Plan Bicentenario. Para fines del presente artículo, amerita una mención especial y un énfasis lo estructurado por el objetivo estratégico $\mathrm{N}^{\circ} 4$ : impulso de la inversión -nacional y extranjera- que influya en el bienestar de la economía, la competitividad y el empleo.

Es menester tener presente que tal objetivo estratégico desprende, entre otros, los siguientes objetivos específicos: i) desarrollo de un marco jurídico e institucional que otorgue garantías y seguridad a la inversión extranjera, ii) fomento del crecimiento económico sostenido mediante la estructuración de una política económica estable y previsora, iii) esquematización de estructuras productivas competitivas, diversificadas, sostenibles y con amplio valor agregado y iv) preservación de mercados eficientes y transparentes en donde concurran instituciones sólidas que promuevan el financiamiento e inversión.

Vale precisar que el objetivo estratégico mencionado y sus objetivos específicos se encuentran plenamente alineados, principalmente, con los Objetivos de Desarrollo Sostenibles (ODS) $\mathrm{N}^{\circ} 8$ (trabajo decente y crecimiento económico) y $\mathrm{N}^{\circ} 17$ (alianzas para lograr objetivos) de la Organización de las Naciones Unidas (ONU). Esto, no cabe duda alguna, refleja, a su vez, un evidente avance del país a efectos de cumplir con los ODS establecidos por la ONU (como parte del proyecto Agenda 2030).

En esa medida, considerando los argumentos previamente expuestos, procedemos a delimitar algunas propuestas de reforma constitucional que podrían llevarse a cabo para tratar de solucionar el dilema señalado sobre el perfeccionamiento interno de los CDI, explicando los alcances que desprende cada caso particular y analizando su viabilidad de materializarse en la realidad.

Por un lado, el primer modelo de reforma constitucional que proponemos se establece en los siguientes términos: 
Los Convenios para evotar la Doble Imposición y su régimen constitucional de perfeccionamiento interno: ¿Una reforma esencial ante el Bicentenario de la República?

\section{Gráfico N²: Comparación entre el marco constitucional vigente y la propuesta de reforma $N^{\circ} 1$ sobre el perfeccionamiento interno de los CDI}

\begin{tabular}{|l|l|}
\hline \multicolumn{1}{|c|}{ Texto constitucional vigente } & \multicolumn{1}{|c|}{ Texto constitucional propuesto } \\
\hline $\begin{array}{l}\text { Art. 56.- Los tratados deben ser } \\
\text { aprobados por el Congreso antes de } \\
\text { su ratificación por el presidente de la } \\
\text { República, siempre que versen sobre } \\
\text { las siguientes materias: }\end{array}$ & $\begin{array}{l}\text { Art. 56.- Los tratados deben ser } \\
\text { aprobados por el Congreso antes de } \\
\text { su ratificación por el presidente de la } \\
\text { República, siempre que versen sobre } \\
\text { las siguientes materias: }\end{array}$ \\
$\begin{array}{l}\text { 1. Derechos Humanos. } \\
\begin{array}{l}\text { 2. Soberanía, dominio o integridad del } \\
\text { Estado. }\end{array}\end{array}$ & $\begin{array}{l}\text { 1. Derechos Humanos. } \\
\text { Estado. }\end{array}$ \\
$\begin{array}{l}\text { 3. Defensa Nacional. } \\
\text { 4. Obligaciones financieras del } \\
\begin{array}{l}\text { Estado. También deben ser aprobados } \\
\text { por el Congreso los tratados que }\end{array} \\
\begin{array}{l}\text { crean, modifican o suprimen tributos; } \\
\text { los que exigen modificación o } \\
\text { derogación de alguna ley y los que } \\
\text { requieren medidas legislativas para } \\
\text { su ejecución. }\end{array}\end{array}$ & $\begin{array}{l}\text { 3. Defensa Nacional. } \\
\text { También deben ser aprobados por el } \\
\text { Congreso los tratados que exigen } \\
\text { modificación o derogación de alguna } \\
\text { ley y los que requieren medidas } \\
\text { legislativas para su ejecución. }\end{array}$ \\
\hline
\end{tabular}

Fuente: Elaboración propia

La finalidad que subyace a esta propuesta se orienta a eliminar los CDI de la lista taxativa de instrumentos internacionales que requieren de aprobación previa por el Congreso para su perfeccionamiento interno. Con ello, se dotará de mayor celeridad al trámite de entrada en vigor del CDI al agilizar el tiempo que transcurrirá entre la fase de suscripción y ratificación del CDI. Con esto, se dejará de lado las atribuciones de responsabilidad al Ejecutivo y/o Legislativo por el retardo en remitir el instrumento o por emitir la resolución legislativa que dispone su aprobación, respectivamente. Cabe precisar, que suprimir el requisito de aprobación previa para el perfeccionamiento interno del CDI (control ex ante) no implica que el mismo se encuentre exento de control. Todo lo contrario, luego de iniciada su vigencia, el Ejecutivo deberá presentar el instrumento para su debida fiscalización por el Congreso a fin de determinar su utilidad y concordancia para con los fines del ordenamiento jurídico, así como para identificar posibles inconsistencias del mismo que puedan afectar gravemente el orden soberano del país, al ser ahora aplicable el control ex post o simplificado de la Constitución bajo este modelo propuesto (al suprimir los CDI de la lista taxativa del artículo $56^{\circ}$, ahora deberán sujetarse a lo predispuesto en el artículo $57^{\circ}$ de la Carta Magna). 
Sin embargo, somos de la opinión que la viabilidad de materializar esta propuesta en la realidad encuentra complicaciones. Ello, porque el texto constitucional del artículo $56^{\circ}$ alcanza no solo a los CDI sino, además, a otros tratados en materia tributaria (por ejemplo, en materia de intercambio de información en materia fiscal, sobre resolución de conflictos, respecto a la distribución de potestad tributaria sobre rentas derivadas de la navegación marítima y aérea, etc.), por lo que suprimir la disposición "también deben ser aprobados por el Congreso los tratados que crean, modifican o suprimen tributos" afectaría tal clase de acuerdos. Del mismo modo, si bien esta primera propuesta de reforma busca alcanzar un estándar de celeridad para el perfeccionamiento interno (aprobación de los CDI), podría ocurrir que se colisione con otros parámetros constitucionales como el principio de legalidad contemplado en el artículo $74^{\circ}$ de la Carta Magna (los tributos se crean, modifican o derogan, o se establece una exoneración, exclusivamente por ley). Una situación de esta naturaleza, como es evidente, no puede aceptarse en el marco de un Estado Constitucional de Derecho.

Es por tales razones que a pesar de la interesante finalidad que involucra la primera propuesta presentada no nos adscribiremos a la misma, debido a las dificultades que emanarían de su eventual aplicación en la realidad.

De otro lado, el segundo bosquejo de reforma constitucional que proponemos responde a la siguiente redacción:

Gráfico N³: Comparación entre el marco constitucional vigente y la propuesta de reforma $N^{\circ} 2$ sobre el perfeccionamiento interno de los CDI

\begin{tabular}{|l|l|}
\hline \multicolumn{1}{|c|}{ Texto constitucional vigente } & \multicolumn{1}{|c|}{ Texto constitucional propuesto } \\
\hline $\begin{array}{l}\text { Art. 56.- Los tratados deben ser } \\
\text { aprobados por el Congreso antes de su } \\
\text { ratificación por el presidente de la } \\
\text { República, siempre que versen sobre } \\
\text { las siguientes materias: }\end{array}$ & $\begin{array}{l}\text { Art. 56.- Los tratados deben ser } \\
\text { aprobados por el Congreso antes de su } \\
\text { República, siempre que versen sobre } \\
\text { las siguientes materias: }\end{array}$ \\
$\begin{array}{l}\text { 1. Derechos Humanos. } \\
\begin{array}{l}\text { 2. Soberanía, dominio o integridad del } \\
\text { Estado. }\end{array}\end{array}$ & $\begin{array}{l}\text { 1. Derechos Humanos. } \\
\text { Estado. }\end{array}$ \\
$\begin{array}{l}\text { 3. Defensa Nacional. } \\
\text { 4. Obligaciones financieras del Estado. dominio o integridad del }\end{array}$ \\
$\begin{array}{l}\text { También deben ser aprobados por el } \\
\text { Congreso los tratados que crean, } \\
\text { modifican o suprimen tributos; los que } \\
\text { exigen modificación o derogación de }\end{array}$ & $\begin{array}{l}\text { También deben ser aprobados por el } \\
\text { Congreso los tratados que crean, } \\
\text { modifican o suprimen tributos; los que } \\
\text { exigen modificación o derogación de }\end{array}$ \\
\hline
\end{tabular}




\begin{tabular}{|c|c|}
\hline $\begin{array}{l}\text { alguna ley y los que requieren } \\
\text { medidas legislativas para su ejecución. }\end{array}$ & 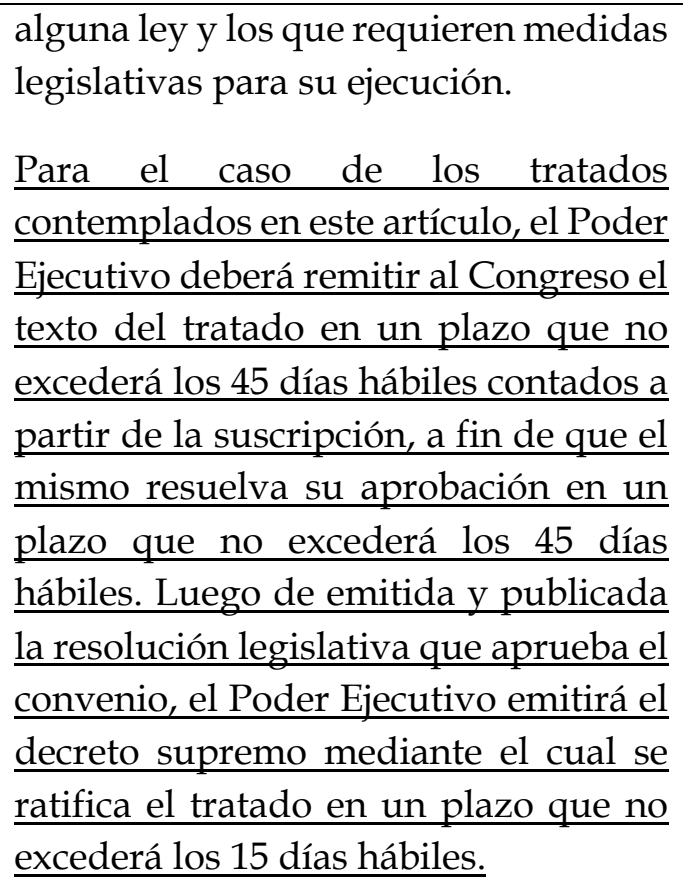 \\
\hline
\end{tabular}

Fuente: Elaboración propia

Mediante este segundo bosquejo de reforma ya no se pretende eliminar los CDI de la lista de tratados que requieren de aprobación previa para su perfeccionamiento interno. El objetivo, ahora, consiste en delimitar una serie de plazos estandarizados que deberán observar, obligatoriamente, tanto el Ejecutivo como el Legislativo para proceder a remitir el instrumento que contiene al tratado internacional (entre ellos, los CDI) como para emitir la resolución legislativa que dispone su aprobación, respectivamente. Bajo esta estructuración persiste la mentalidad de conceder mayor celeridad al trámite de entrada en vigor del CDI, producto de acelerar el tiempo que transcurrirá entre la fase de suscripción y ratificación del CDI.

Ahora bien, consideramos que la viabilidad de esta segunda propuesta sí encuentra fundamento. Ello, porque este bosquejo no se orienta a modificar sustancialmente la línea original de la Constitución, a comparación del modelo precedente, en donde se pretendía retirar el requisito de aprobación previa por el Congreso a los CDI (lo cual podía llegar a afectar a la totalidad de tratados tributarios). Asimismo, la aplicación de los plazos estandarizados será transversal a la totalidad de materias incluidas en el artículo $56^{\circ}$ de la Constitución (derechos humanos, materia tributaria, obligaciones financieras, etc.) y no se concentrará en una materia exclusiva (CDI). Esto último refleja un enfoque integral en la concepción del derecho de los tratados, distanciándonos de cualquier clase de sesgo sobre el particular. Además, no se advierte algún tipo de colisión con algún principio y/o valor fundamental consagrado por la Constitución.

Considerando todo lo anteriormente expuesto, manifestamos nuestra plena suscripción en poder llevar a cabo esta propuesta en la realidad. 
A modo de complemento, un tercer modelo de reforma constitucional puede enmarcarse en la siguiente lectura que sigue a continuación:

Gráfico $N^{\circ} 4$ : Comparación entre el marco constitucional vigente y la propuesta de reforma $N^{\circ} 3$ sobre el perfeccionamiento interno de los CDI

\begin{tabular}{|c|c|}
\hline Texto constitucional vigente & Texto constitucional propuesto \\
\hline $\begin{array}{l}\text { Art. 56.- Los tratados deben ser } \\
\text { aprobados por el Congreso antes de su } \\
\text { ratificación por el presidente de la } \\
\text { República, siempre que versen sobre } \\
\text { las siguientes materias: } \\
\text { 1. Derechos Humanos. } \\
\text { 2. Soberanía, dominio o integridad del } \\
\text { Estado. } \\
\text { 3. Defensa Nacional. } \\
\text { 4. Obligaciones financieras del Estado. } \\
\text { También deben ser aprobados por el } \\
\text { Congreso los tratados que crean, } \\
\text { modifican o suprimen tributos; los que } \\
\text { exigen modificación o derogación de } \\
\text { alguna ley y los que requieren } \\
\text { medidas legislativas para su ejecución. }\end{array}$ & 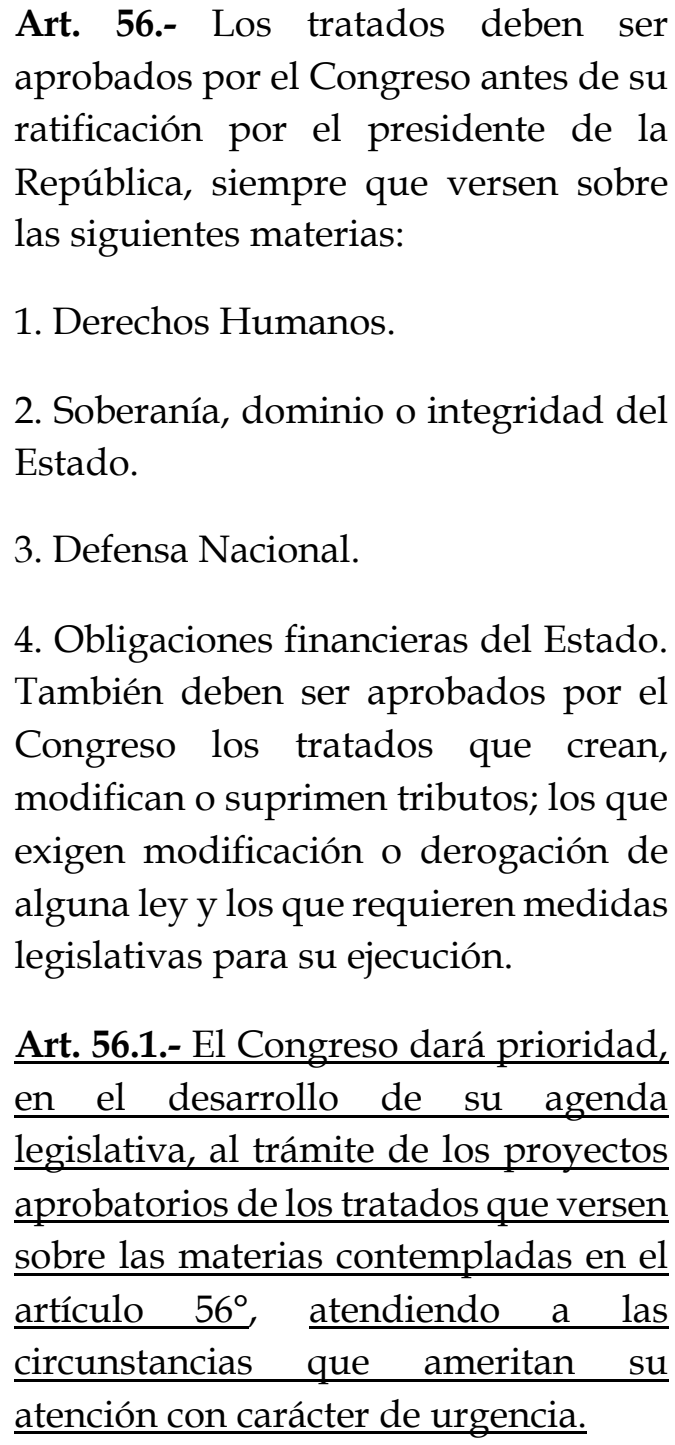 \\
\hline
\end{tabular}

Fuente: Elaboración propia

Mediante este tercer bosquejo, se preserva el requisito de aprobación previa para el perfeccionamiento interno de los CDI. Se pretende exhortar a un ente específico (Legislativo) para que otorgue prioridad, en su agenda legislativa, a los proyectos aprobatorios sobre tratados internacionales (entre ellos, los CDI) que le sean sometidos por parte del Ejecutivo, a fin de llevar a cabo, céleremente, su función de examen sobre el contenido y posterior emisión de la resolución legislativa de aprobación, teniendo en cuenta que las circunstancias que envuelven a la temática de tratados contemplados en el artículo $56^{\circ}$ son aquellos que, con mayor frecuencia, se celebran por parte de la congregación internacional (incluyendo al 
Perú). Vale precisar que, a diferencia de la segunda propuesta de reforma constitucional, este bosquejo actúa de forma genérica y no bajo algún plazo definido, considerando la eventual manifestación de críticas por intentar impulsar diversos regímenes que establezcan tiempos perennes si se tiene en cuenta la excesiva carga administrativa que manejan los poderes del Estado.

Ahora bien, respecto a la factibilidad de esta propuesta, consideramos que la misma sí encuentra cabida. Antes de todo, debemos precisar que la incorporación de este artículo 56.1 dispone como antecedente una interesante disposición de la Constitución de Colombia de 199138. Si bien la redacción se asemeja, existe una diferencia sustancial entre ambos preceptos, ya que mientras la Carta de Magna de Colombia buscar instar al Legislativo para que otorgue prioridad al tratamiento legislativo de los instrumentos internacionales que versen sobre una de las principales ramas de interés y preocupación para la sociedad internacional (derechos humanos), nuestra proposición de reforma es transversal a la totalidad de materias contenidas en el artículo $56^{\circ}$ de la Constitución (derechos humanos, obligaciones financieras, CDI, etc.). En la misma línea, ante la hipotética implementación de esta propuesta en conjunto con el modelo precedente (sobre la cual manifestamos nuestra plena adscripción), consideramos que su lectura debe efectuarse de forma integral y concordada, debido a que esto nos permitirá preservar una visión uniforme e idónea sobre la concepción del derecho de los tratados.

Por lo expuesto, expresamos nuestra suscripción para que esta propuesta de reforma constitucional pueda materializarse en la realidad.

Otro aspecto relevante por abordar es la mecánica constitucional para llevar a cabo las reformas sobre las que determinamos su viabilidad de aplicación en la realidad. Para ello, debemos remitirnos al artículo 206 . El mismo nos instruye que la iniciativa para la presentación de un proyecto de reforma constitucional corresponde: i) al presidente de la república con aprobación del consejo de ministros, ii) a los congresistas y iii) a un número de ciudadanos equivalente al $0.3 \%$ de la población electoral con firmas debidamente comprobadas por la autoridad electoral. Posterior a la presentación de la iniciativa, la misma deberá ser aprobada por el Legislativo con mayoría absoluta del número legal de sus miembros (66 votos de los 130 posibles), además de ser ratificada a través de un referéndum. Esto último podría omitirse sí y solo si el acuerdo aprobatorio de la reforma se alcanza en dos legislaturas ordinarias sucesivas con una votación favorable, en ambos casos, que supere los dos tercios del número legal de congresistas $(87 \text { votos })^{39}$.

Sin perjuicio de todo lo expuesto hasta esta parte, no podría faltar un lector que aún mantenga dudas sobre la necesidad de que el Legislativo impulse una

38 Artículo 164. - El Congreso dará prioridad al trámite de los proyectos de ley aprobatorios de los tratados sobre derechos humanos que sean sometidos a su consideración por el Gobierno.

39 CHANAMÉ ORBE, Raúl. La Constitución de todos los peruanos. Lima: Fondo editorial cultura peruana, 2011. 
modificación constitucional vinculada con un artículo que se ha mantenido inalterado desde 1993, partiendo de un caso específico como el de los CDI.

Sobre el particular, si bien el texto del artículo $56^{\circ}$ de la Constitución no ha sido objeto de modificaciones desde su promulgación en 1993 (un aproximado de 28 años) y, en consecuencia, ha sido empleado ante el sometimiento de todo tratado que se enmarque en su ámbito de aplicación (incluidos los CDI vigentes a la fecha), no es menos cierto recordar que toda Constitución, al igual que el ser humano, es en sí misma incompleta y se encuentra lejos de alcanzar un estatus de perfección. Las circunstancias que concurrieron al momento de la publicación de la norma no necesariamente serán las mismas transcurrido un período de tiempo determinado.

Las expectativas cambian y, al mismo tiempo, surgen nuevas problemáticas. Al momento de emitirse la Norma Suprema de 1993 se aspiraba congregar un repertorio de tratados sobre materias específicas que uniformicen tanto el resguardo de aspectos elementales para garantizar una vida en sociedad (protección de derechos humanos, integridad estatal, etc.) como la promoción de mejoras en el curso económico, institucional y/o social del país en general (CDI, asunción de obligaciones financieras, etc.).

En ese sentido, si tal aspiración del legislador constitucional falló en cierta forma debido a un supuesto concreto (bajo el régimen actual disponemos de una escasa red de CDI), se torna en evidente que debe intentarse articular algún mecanismo de solución para este dilema, siempre y cuando ello no colisione con otros valores $\mathrm{y}$ principios que emanan del texto constitucional $\mathrm{y}$, en general, se respete la integridad y concordancia inherente a nuestra Carta Magna en aras de dotar de viabilidad su eventual producción en la realidad. Justamente, tales presupuestos lo cumplen a cabalidad las propuestas de reforma constitucional $\mathrm{N}^{\circ} 2$ y $\mathrm{N}^{\circ} 3$ que expusimos anteriormente.

Son en estos argumentos, entonces, los que nos permiten enfatizar en la posición de impulsar una modificación constitucional sobre un artículo que ha permanecido inalterado desde la promulgación de la actual Norma Suprema, a partir de una materia concreta de acuerdos internacionales: los CDI.

Finalmente, la elección indistinta de las propuestas legislativas desarrolladas facilitará aproximarnos a una serie de expectativas que pueden ejercer los CDI como parte del cumplimiento de los objetivos estratégicos del Plan Bicentenario y, en general, de cara al porvenir: i) coadyuvará con el afronte adecuado de las nuevas tendencias en el derecho tributario internacional (el desarrollo de los establecimientos permanentes virtuales o no físicos a partir del criterio de la presencia económica significativa de la $\mathrm{OCDE}^{40}$ ), ii) colaborará con la lucha contra la trampa de los ingresos medios en el Perú (luchar contra esta situación

40 Para comprender la figura del establecimiento permanente virtual a partir del criterio de la presencia económica significativa, recomendamos ver: OCDE. El Enfoque Unificado: La Propuesta del Secretariado relativa al Primer Pilar. 9 de octubre - 12 de noviembre de 2019, OCDE, https:// www.oecd.org/tax/beps/documento-para-consulta-publica-el-enfoque-unificado-lapropuesta-del-secretariado-relativa-al-primer-pilar.pdf 
infructífera en la que se inserta la economía de un país ${ }^{41}$ puede lograrse mediante el fomento de la inversión que busca incentivar los CDI) y iii) cooperará con la ampliación del repertorio de medidas que impulsen la reactivación económica y social ante los perjuicios generados por el Covid-19.

\section{Reflexión final}

En las presentes líneas, determinamos que la doble imposición se presenta como una situación perniciosa que afecta al contribuyente, la igualdad de las rentas, la recaudación efectiva de un Estado, entre otros aspectos, ya sea desde su faceta económica como jurídica. Los CDI aparecían como uno de los principales instrumentos que utilizan los países para tratar de contrarrestar los efectos adversos que nos presenta la citada doble imposición. Producto de ello, la perspectiva que manejaría todo Estado sería ampliar ágilmente su red de CDI no solo para combatir situaciones de doble imposición, sino, además, para alcanzar la diversidad de beneficios que esta clase de convenios supranacionales nos presenta.

El Perú no debía ser la excepción a esta regla. Sin embargo, nuestra realidad demostraba que el repertorio de CDI se encontraba lejos de alcanzar un estándar de idoneidad, tanto en términos cuantitativos como cualitativos, si tomábamos como ejemplo el esquema de CDI en otros países de la región latinoamericana y pertenecientes a la OCDE (México, Chile y Colombia), los cuales eran sustancialmente mejores a comparación del Perú.

Bajo esta premisa, fue necesario desmenuzar los aspectos que motivaban la problemática expuesta. Gracias a ello, se pudo comprobar que un factor clave (sin perjuicio de la existencia de otros) que impedía otorgar un trámite de celeridad a la suscripción y subsecuente ratificación de los CDI, en el hoy en día, recaía en el marco constitucional para su perfeccionamiento interno (aprobación previa por el Congreso, conforme los términos del artículo $56^{\circ}$ ). Este parámetro delimitaba en la práctica una serie de obstáculos que impedían acelerar el transcurso de la etapa de suscripción a la ratificación del CDI para su posterior entrada en vigor.

En ese sentido, planteamos tres propuestas para la modificación del régimen constitucional para el perfeccionamiento interno de los CDI en el Perú (desvirtuando la viabilidad de la primera y suscribiendo la factibilidad de las otras dos), considerando que la temática adquiere relevancia no solo por su connotación nacional para fines supranacionales (el ingreso de la Perú a la OCDE), sino también por el panorama que afronta nuestro país actualmente (el Bicentenario de La República).

41 Un análisis exhaustivo sobre la incidencia de la trampa de los ingresos medios en el continente latinoamericano lo desarrollamos en la ponencia "El dilema de los ingresos medios en Latinoamérica ante la pandemia: alternativas para una mejoría continental", la cual fue presentada en el $1^{\circ}$ Congreso Latinoamericano "Crisis Mundial y Geopolítica: Pensar y construir el multipolarismo y el pluriversalismo para un nuevo orden mundial" organizado por el Centro de Investigaciones en Política y Economía y el Observatorio Internacional de la Crisis y llevado a cabo en formato virtual durante los meses de noviembre y diciembre de 2020. 
A partir de todo lo expuesto, podemos inferir que la agenda pendiente en torno al régimen de los CDI en el Perú seguirá siendo la misma hacia el porvenir: ampliar nuestro repertorio de CDI, además de fortalecer los ya vigentes. El logro de esta aspiración puede alcanzarse de varias formas. En este trabajo, mediante las reflexiones desarrolladas, buscábamos lograr el objetivo mediante la proposición de ciertos tópicos estructurados en bosquejos de reforma constitucional bajo perspectivas claramente delineadas.

Sin perjuicio que los términos de las propuestas de reforma constitucional anteriormente delineadas (tanto sobre las dos que manifestamos nuestra adhesión como aquella sobre la que expresamos nuestras críticas por no ser viable) sean de aceptación unánime, parcial o se propongan nuevos bosquejos de reforma, lo que sí debe quedar claro es lo imprescindible de manifestar ideas que coadyuven con la mejora de la estabilidad social, económica e institucional del país, tanto para cumplir con las expectativas que demanda el Bicentenario de La República como para mejorar la estructura tributaria interna en aras de alcanzar el ansiado ingreso del Perú de la OCDE. Asimismo, no olvidemos tener en cuenta que el análisis de la problemática de los CDI y el planteamiento de alternativas de solución -desde una óptica constitucional u otra visión jurídica- siempre deberá llevarse a cabo bajo enfoques de gobernabilidad democrática y gobernanza global.

Solo así se podrá avanzar idónea, progresiva y sostenidamente, en el camino anhelado. Tenemos la certeza de ello. 